\title{
PENGARUH PENGEMBANGAN KARIR, IKLIM ORGANISASI, DAN KEPUASAN KERJA TERHADAP PROFESIONALITAS KARYAWAN UNIVERSITAS NEGERI
}

\author{
Marus Suti \\ Universitas Negeri Makassar, Jln. A.P. Pettarani Makassar \\ e-mail: marsusayuti@yahoo.com
}

\begin{abstract}
The staff's professionalism is assumed to be affected by the variation their career Development, organizational climate and their job satisfaction. The aim of the experimental study reported here was to test the hypothesis. The causal study was conducted in Makassar State University, from June to October 2009, involving a sample of 120, which had been selected from the overall 566 staff members of the university, by using the simple random sampling technique. Data of each variabel were collected through a survey and analysed descriptively and inferentially through the path analysis. Results show direct and positive effects of career development and organisational climate, respectively, on their job satisfaction. Result alto show indirect effects of the staff's career development on the professionalism through job satisfaction, and of organizational climate on the staff's career development, job satisfaction, and their perception of the organizational climate in the strategis Plan of Makassar State University to improve profesional human resource.
\end{abstract}

Keywords: career development, organisational climate, job satisfaction, and profstaessionality.

Abstrak: Keprofesioanalan staf diasumsikan dapat dipengaruhi oleh variasi pengembangan karier mereka, iklim organisasi, dan kepuasan kerja merak. Tujuan dari penelitian eksperimen ini adalah untuk menguji hipotesis. Penelitian ini dilaksanakan di Universitas Negeri Makassar, dari bulan Juni hingga Oktober 2009, yang melibatkan 120 sampel, yang dipilih dari 566 anggota staf Universitas, dengan menggunakan teknik simple random sampling. Data dari masing-masing variabel dikumpulkan melalyi survey dan analisis secara deskriptif dan inferensial melalui path analysis. Hasil menunjukkan secara langsung dan positif pengaruh dari pengembangan karier dan iklim organisasi pada pengembangan karier staf, kepuasan kerja, dan persepsi mereka terhadap iklim organisasi dalam rencana strategis dai Universutitas Negeri Makassar untuk meningkatkan sumber manusia yang profesional.

Kata Kunci: perkembangan karier, iklim organisasi, kepuasan kerja, dan profesionalitas

\section{PENDAHULUAN}

Kebijakan pemerintah tentang desentralisasi dan otonomi pendidikan yang mulai diberlakukan sejak tahun 2000, menuntut para pimpinan lembaga pendidikan tinggi agar mampu menciptakan programprogram yang inovatif, memiliki nilai jual, dan meningkatkan pelayanan. Melalui program yang inovatif, lembaga pendidikan akan dapat memperbesar sumber-sumber pendapatannya.
Hal ini berarti bahwa dalam rangka meningkatkan pendapatannya, lembaga pendidikan harus berupaya meningkatkan pelayanan terhadap beragam pemangku kepentingan (stakeholders).

Salah satu upaya meningkatkan kualitas pelayanan adalah dengan mengoptimalkan kerja sama yang lebih bersinergi antara seluruh komponen sivitas akademika. Komponen sivitas akademika adalah dosen, 
mahasiswa dan karyawan atau tenaga administrasi. Jika dikategorikan ke dalam jenis aktivitasnya, tugas pokok dosen adalah mengajar meneliti dan mengadakan pengabdian kepada masyarakat, tugas pokok mahasiswa adalah kuliah dan belajar meneliti, sedangkan tugas pokok karyawan atau tenaga administrasi adalah memberikan pelayanan administrasi kepada dosen dan mahasiswa.

Posisi strategis tersebut membuat kelompok karyawan juga berperan penting dalam meningkatkan kualitas pendidikan. Hal tersbeut cukup beralasan sebab seluruh catatan kegiatan akademik ada di tangan mereka. Catatan-catatan tersebut merupakan basis untuk memperbaiki kegiatan akademik di masa yang akan datang gas lebih mengarah pada tujuan pendidikan yang diterapkan. Dengan demikian, peningkatan kualitas pelayanan pendidikan, khususnya pendidikan tinggi, pada dasarnya juga arus melibatkan peran serta para karyawan.

Upaya meningkatkan pelayanan para karyawan tidak hanya meningkatkan keramahtamahan dalam berkomunikasi dengan dosen dan mahasiswa, tetapi juga menyempurnakan sistem pelayanannya agar dapat memuaskan harapan pihak yang dilayaninya. Tantangan tersebut terasa makin berat jika dikaitkan dengan upaya semua lembaga pendidikan tinggi untuk menciptakan penyelenggaraan administrasi yang baik dan bersih (clean and good governance). Agar dapat terlaksana dengan baik, sistem yang ada harus senantiasa dievaluasi dan disempurnakan sehingga dapat mendukung efektivitas pelayanan organisasi pendidikan tinggi secara keseluruhan terhadap dosen, mahasiswa, dan pemangku kepentingan lainnya.

Memasuki era globalisasi, faktor profesionalitas karyawan makin diperlukan. Pernyataan tersebut paling tidak didasarkan pada lima argumentasi dasar. Pertama, sejalan dengan terjadinya percepatan perkembangan teknologi informatika, para dosen, mahasiswa, dan pemangku kepentingan lain menuntut penyebaran arus informasi yang sangat cepat, tepat, dan akurat. Hal ini memungkinkan untuk dapat dilaksanakan dengan adanya perangkat komputer. Persoalan berikutnya adalah karyawan harus mahir dan terampil menggunakan perangkat tersebut. Kemampuan menggunakan perangkat informasi tersebut menjadi salah satu tolak ukur profesionalitas dewasa ini. Kedua, sejalan dengan semangat untuk membangun lembaga pendidikan tinggi yang baik dan bersih (good and clean governance) semua kegiatan lembaga harus tercatat dan hasilnya harus terukur. Untuk lembaga pendidikan tinggi, pihak yang mencatat dan mengukur hasil tersebut merupakan tanggung hawa karyawan administrasi. Dengan demikian, para karyawan mutlak harus meningkatkan profesionalitasnya agar tanggung jawab tersebut dapat terlaksana dengan baik. Ketiga, melalui peningkatan profesionalitas, para karyawan administrasi akan dapat memelihara transparansi pengelolaan keuangan lembaga sesuai dengan peraturan yang berlaku. Keempat, pertumbuhan jumlah mahasiswa dan perkembangan program studi baru yang makin meningkat setiap tahunnya akan menjadi tantangan tersendiri bagi karyawan untuk meningkatkan profesionalitasnya agar senantiasa dapat meningkatkan pelayanannya kepada pihak terkait. Terakhir, seperti yang telah diuraikan sebelumnya, pihak karyawan juga menjadi salah satu pihak yang tidak dapat diabagikan dalam peningkatan kualitas pendidikan nasional. Hal ini berarti bahwa peningkatan profesionalitas karyawan merupakan bagian integral dari peningkatan kualitas pendidikan nasional.

Berbagai upaya telah dilakukan oleh pihak Universitas untuk meningkatkan profesionalitas karyawan, di antaranya adalah dengan (a) mengirimkan para karyawan mengikuti pendidikan dan pelatihan yang diselenggarakan oleh instansi terkait; (b) 
memberikan kesempatan kepada pihak karyawan untuk meningkatkan pendidikan formal; dan (c) menerapkan konsep manajemen mutu total (total quality Management/TQM) pada setiap unit kerja masing-masing. Sesuai dengan konsep TQM, para karyawan dibagi ke dalam gugus-gugus kendali mutu dan diharapkan akan mampu melahirkan ide-ide baru yang dapat meningkatkan pelayanan institusinya. Meskipun demikian, upaya untuk membina dan memupuk profesionalitas karyawan dinilai masih belum cukup mengingat tantangan di masa yang akan datang masih sangat berat, seperti dengan diterapkannya sistem Teknologi Informasi dan Komunikasi (TIK) atau Information and Communication Technology (ICT).

Upaya lain yang perlu dilakukan untuk meningkatkan profesionalitas karyawab adalah melalui pendekatan ilmiah. Hal tersebut dapat dilakukan dengan mengidentifikasi faktorfaktor yang berhubungan dengan profesionalitas dan mengujinya secara empirik. Hasil kajian tersebut kelak akan dapat dijadikan dasar untuk meningkatkan profesionalitas karyawan pada setiap lembaga pendidikan tinggi pada umumnya dan Universitas Negeri Makassar khususnya.

Berdasarkan hasil kajian pendahuluan (preliminary study) faktor-faktor yang diduga terkait dengan upaya peningkatan profesionalitas karyawan antara lain adalah: (1) disiplin kerja; (2) sistem imbalan; (3) sistem seleksi; (4) integritas pribadi; (5) motivasi belajar; (6) keterampilan berkomunikasi; (7) rasa percaya diri; (8) motivasi berprestasi; (9) kecerdasan emosional; (10) budaya kerja organisasi; (11) pengembangan karier; (12) iklim organisasi; dan (13) kepuasan kerja.

\section{METODOLOGI PENELITIAN}

Populasi penelitian ini adalah karyawan yang bekerja di perguruan tinggi, kerangka sampelnya (sample frame)dibatasi hanya pada karyawan yang bekerja di Universitas Negeri Makassar sebesar 556 karyawan. Sampel penelitian ditarik dari kerangka sampel sebanyak 120 karyawan dengan teknik pengambilan sampel acak sederhana (simple random sampling). Penelitian ini dilakukan terhadap para karyawan di Universitas Negeri Makassar dari bulan Juni 2009 hingga bulan Oktober 2009. Metode yang digunakan adalah metode survei dengan menggunakan analisis jalur (Path Analysis), di mana hubungan kausal dilakukan untuk menguji pengaruh langsung maupun tidak langsung pengembangan karier, iklim organisasi, kepuasan kerja terhadap profesionalitas.

Penelitian ini bertujuan untuk mengetahui dan menguji ada tidaknya: (1) pengaruh langsung pengembangan karier terhadap profesionalitas; (2) pengaruh langsung iklim organisasi terhadap profesionalitas; (3) pengaruh langsung kepuassan kerja terhadap profesionalitas; (4) pengaruh langsung pengembangan karir terhadap kepuasan kerja; (5) pengaruh langsung iklim organisasi terhadap kepuasan kerja; (6) pengaruh tidak langsung pengembangan karier terhadap profesionalitas melalui kepuasan kerja; dan (7) pengaruh tidak langsung iklim organisasi terhadap profesionalitas melalui kepuasan kerja.

Sesuai dengan uraian di atas, model analisis jalur yang digali dalam penelitian ini dapat digambarkan sebagai berikut. 


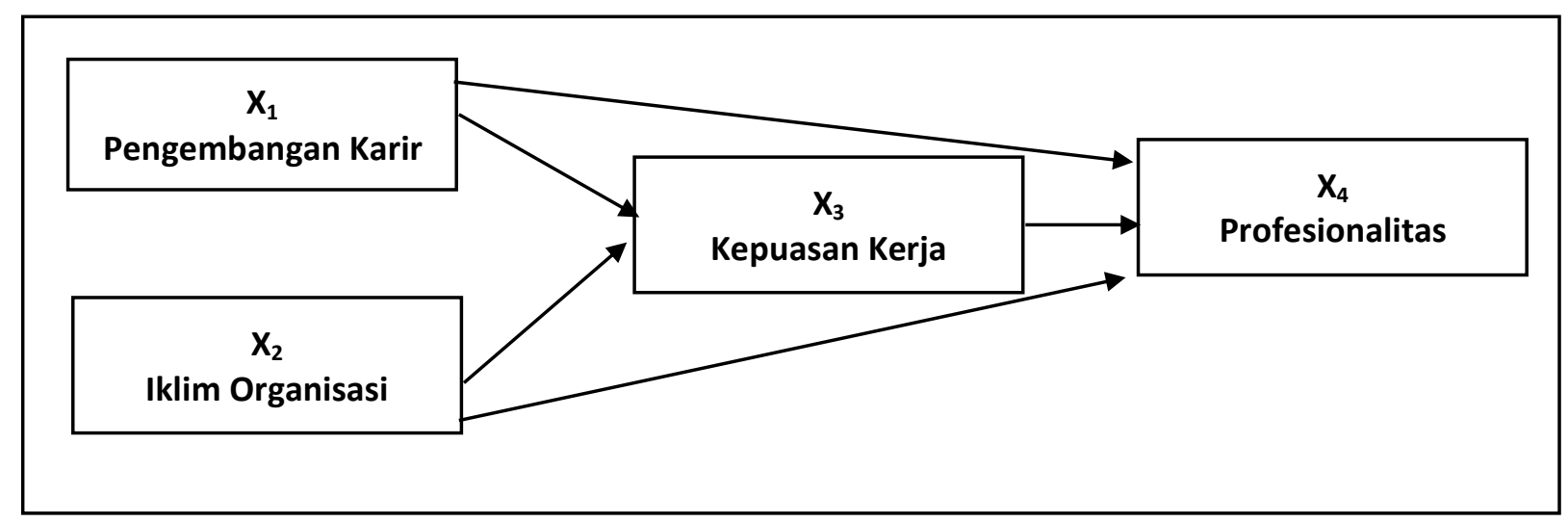

Gambar 1. Model Analisis Jalur

Untuk menjaring data, penelitian ini menggunakan instrumen berupa kuesioner yang dikembangkan sendiri oleh peneliti dan telah diujicobakan untuk menilai validitas dan reliabiltasnya. Pengukuran validitas butir instrumen menggunakan rumus korelasi Product moment. Hasil uji coba memperlihatkan bahwa reliabilitas kuesioner profesionalitas $\left(\mathrm{X}_{1}\right)=0,961$; reliabiltas kuesioner pengembangan karir $=0,948$; reliabilitas kuesioner kepuasan kerja = 0,751 . Sesuai dengan perhitungan tersebut, keseluruhan instrumen penelitian ini adalah angan reliabel dan layak digunakan untuk menjaring data penelitian.

\section{HASIL DAN PEMBAHASAN}

syarat analisis jalur (path analysis) adalah hubungan antar variabel dalam model harus linear, sehingga dapat memenuhi persyaratan analisis regresi.

\section{Uji Normalitas}

Pengujian normalitas galat taksiran regresi $\mathrm{Y}$ atas $\mathrm{X}$ bertujuan untuk menguji normalitas populasi. Ketentuan pengujiannya adalah galat taksiran $(\mathrm{Y}-\widehat{Y})$ harus berdistribusi nol. Dengan kata lain, jika $\mathrm{H}_{\mathrm{o}}$ diterima, maka populasi berdistribusi normal. Sebaliknya, jika $\mathrm{H}_{\mathrm{o}}$ ditolak, berarti populasi tidak terdistribusi normal. Pengujian persyaratan normalitas galat taksiran variabel terikat terhadap variabel bebas dilakukan dengan menggunakan uji Lilliefors. Dengan ketentuan: $\mathrm{H}_{\mathrm{o}}$ diterima, jika $\mathrm{L}_{\text {hitung }}<\mathrm{L}_{\text {tabel }}$ dan $\mathrm{H}_{\mathrm{o}}$ ditolak, jika $\mathrm{L}_{\text {hitung }}>\mathrm{L}_{\text {tabel. }}$ Uji Normalitas Galat Taksiran Regresi Langkah awal untuk uji normalitas galat taksiran $\mathrm{X}_{4}$ atas $\mathrm{X}_{1}$ adalah menghitung nilainilai $\mathrm{Y}, \widehat{\mathrm{Y}}$, dan $(\mathrm{Y}-\widehat{\mathrm{Y}})$ berdasarkan persamaan regresi $\mathrm{X}_{4}=78,26+0,43 \mathrm{X}_{1}$. Kemudian dilanjutkan dengan menghitung nilai zi, $\mathrm{F}(\mathrm{zi}), \mathrm{S}(\mathrm{ji})$. L-hitung nya diambil dari nilai $\mathrm{L}$ tertinggi. Berdasarkan hasil analisis data, diketahui bahwa nilai $L$ tertinggi atau $\mathrm{L}_{\text {-hitung }}$ $=0,08005<\mathrm{L}_{\text {-tabel }}(0,08091)$ yang berarti persamaan regresi $\mathrm{X} 4=78,26+0,43 \mathrm{X} 1$ berasal dari populasi yang berdistribusi normal.

Uji Normalitas Galat Taksiran Regresi $\mathbf{X}_{4}$ atas $X_{2}$ persamaan $X_{4}=100,03+0,21 X_{2}$

Mengikuti proses yang telah dijelaskan sebelumnya, uji normalitas galat taksiran regresi $\mathrm{X}_{4}$ atas $\mathrm{X}_{2}$ berdasarkan persamaan regresi $X_{4}=100,03+0,21 X_{2}$ menghasilkan $\mathrm{L}_{\text {-hitung }}=0,07732$. Nilai $\mathrm{L}_{\text {-tabel }}=0,08091$ pada $\alpha=0,05$. Berdasarkan temuan ini dapat disimpulkan bahwa secara empirik galat taksiran dari persamaan regresi $\mathrm{X}_{4}=100,03$ $+0,21 X_{2}$ juga berasal dari populasi yang berdistribusi normal. 
Uji Normalitas Galat Taksiran Regresi $\mathrm{X}_{4}$ atas $X_{3}$ persamaan $X_{4}=\mathbf{9 0 , 8 3}+\mathbf{0 , 4 6} X_{3}$

Dengan menerapkan proses yang sama pada persamaan regresi $X_{4}=90,82+0,46 X_{3}$ memiliki $\mathrm{L}_{\text {-hitung }}=0,07963$. Nilai ini lebih kecil dari $\mathrm{L}_{\text {-tabel }}=0,08091$ yang berarti galat taksiran dari persamaan regresi $\mathrm{X}_{4}=74,63+$ $0,29 \quad \mathrm{X}_{3}$ berasal dari populasi yang berdistribusi normal.

Uji Normalitas Galat Taksiran Regresi $\mathbf{X}_{3}$ atas $X_{1}$ persamaan $X_{3}=33,40+0,49 X_{1}$

Dengan menerapkan proses yang sama pada persamaan regresi $X_{3}=33,40+0,49 X_{3}$ memiliki $\mathrm{L}_{\text {-hitung }}=0,08003$. Nilai ini lebih kecil dari $\mathrm{L}_{\text {-tabel }}=0,08091$ yang berarti galat taksiran dari persamaan regresi $\mathrm{X}_{3}=33,40+$ $0,49 \mathrm{X}_{1}$ berasal dari populasi yang berdistribusi normal.

Uji Normalitas Galat Taksiran Regresi $\mathbf{X}_{3}$ atas $X_{2}$ persamaan $X_{3}=48,26+0,43 X_{2}$

Dengan menerapkan proses yang sama pada persamaan regresi $\mathrm{X}_{3}=48,26+0,43 \mathrm{X}_{2}$ memiliki $L_{\text {-hitung }}=0,07921$. Nilai ini lebih kecil dari $\mathrm{L}_{\text {-tabel }}=0,08091$ yang berarti galat taksiran dari persamaan regresi $\mathrm{X}_{3}=48,26+$ $0,43 \mathrm{X}_{2}$ berasal dari populasi yang berdistribusi normal

Rangkuman hasil perhitungan normalitas ini dapat dilihat pada Tabel 1 berikut.

Tabel 1. Rangkuman Analisis Uji Normalitas Galat Taksiran (n=120)

\begin{tabular}{|c|c|c|c|c|}
\hline $\begin{array}{c}\text { Galat } \\
\text { Taksiran }\end{array}$ & n & t-hitung & t-tabel & keterangan \\
\hline $\mathrm{X}_{4}$ atas $\mathrm{X}_{1}$ & 120 & 0,08005 & 0,08091 & Normal \\
\hline $\mathrm{X}_{4}$ atas $\mathrm{X}_{2}$ & 120 & 0,07732 & 0,08091 & Normal \\
\hline $\mathrm{X}_{4}$ atas $\mathrm{X}_{3}$ & 120 & 0,07963 & 0,08091 & Normal \\
\hline $\mathrm{X}_{3}$ atas $\mathrm{X}_{1}$ & 120 & 0,08003 & 0,08091 & Normal \\
\hline $\mathrm{X}_{3}$ atas $\mathrm{X}_{2}$ & 120 & 0,07921 & 0,08091 & Normal \\
\hline
\end{tabular}

\section{Keterangan:}

$\mathrm{X}_{1}=$ Pengembangan Karir

$\mathrm{X}_{2}=$ Iklim Organisasi

$\mathrm{X}_{3}=$ Kepuasan Kerja

$\mathrm{X}_{4}=$ Profesionalitas

Uji Linearitas

Uji linearitas dan signifikansi regresi dilakukan melalui uji regresi univariat, yaitu uji linearitas dan signifikansi koefisien regresi berdasarkan jalur yang telah dikonstruksikan. Jalur tersebut adalah: (1) pengembangan karier $\left(\mathrm{X}_{1}\right)$ dengan profesionalitas $\left(\mathrm{X}_{4}\right)$; (2) iklim organisasi $\left(\mathrm{X}_{2}\right)$ dengan profesionalitas $\left(\mathrm{X}_{4}\right)$; (3) kepuasan kerja $\left(\mathrm{X}_{3}\right)$ dengan profesionalitas $\left(\mathrm{X}_{4}\right)$; (4) pengembangan karir $\left(\mathrm{X}_{1}\right)$ dengan kepuasan kerja $\left(\mathrm{X}_{3}\right)$; dan (5) iklim organisasi $\left(\mathrm{X}_{2}\right)$ dengan kepuasan kerja $\left(\mathrm{X}_{3}\right)$.

Uji ini dimaksudkan untuk melihat persamaan regresi pasangan variabel yang diteliti secara individual dengan asumsi bahwa jika secara individual semua pasangan memperlihatkan gejala-gejala pergerakan yang sama, maka hal itu juga akan terjadi Ika dilakukan kajian secara keseluruhan. Analisis regresi univariat untuk masing-masing pasangan variabel tersebut dapat diuraikan sebagai berikut.

Uji Linearitas Profesionalitas $\left(\mathrm{X}_{4}\right)$ atas Budaya Organisasi $\left(\mathbf{X}_{1}\right)$

Sama dengan proses yang telah diuraikan sebelumnya, dari hasil analisis data diketahui bahwa koefisien arah regresi $b$ adalah 0,43. Harga konstanta a diperoleh sebesar 78,26. Berdasarkan hasil perhitungan tersebut, bentuk hubungan pasangan variabel ini dapat digambarkan 
melalui persamaan regresi $\mathrm{X} 4=78,26+$ $0,43 X 1$. Uji keberartian dan kelinearan persamaan regresinya dirangkum pada Tabel 4.7 berikut

ini:

Tabel 2. Rangkuman Hasil Analisis Signifikansi dan Linearitas Persamaan Regresi

\begin{tabular}{|c|c|l|}
\hline Pasangan Variabel & Persamaan Regresi & \multicolumn{1}{c|}{ Kesimpulan } \\
\hline $\mathrm{X}_{1}-\mathrm{X}_{4}$ & $\mathrm{X}_{4}=78,26+0,43 \mathrm{X}_{1}$ & Signifikan dan Linear \\
\hline $\mathrm{X}_{2}-\mathrm{X}_{4}$ & $\mathrm{X}_{4}=100,03+0,21 \mathrm{X}_{2}$ & Signifikan dan Linear \\
\hline $\mathrm{X}_{3}-\mathrm{X}_{4}$ & $\mathrm{X}_{4}=90,83+0,45 \mathrm{X}_{3}$ & Signifikan dan Linear \\
\hline $\mathrm{X}_{1}-\mathrm{X}_{3}$ & $\mathrm{X}_{3}=33,40+0,49 \mathrm{X}_{1}$ & Signifikan dan Linear \\
\hline $\mathrm{X}_{2}-\mathrm{X}_{3}$ & $\mathrm{X}_{3}=48,26+0,43 \mathrm{X}_{2}$ & Signifikan dan Linear \\
\hline
\end{tabular}

\section{Pengujian Model}

Uji kesesuaian model ini adalah dengan menggunakan perhitungan indeks kesesuaian model (Goodness of Fit Indices/ GFI) sebagai numerator dan indeks kesesuaian model yang disesuaikan (Adjusted Goodness of Fit Indices/AGFI) sebagai denumerator. Kriteria pengujiannya adalah

(a) Jika harga GFI dan AGFI mendekati angka 1, berarti model yang dikonstruksikan telah sesuai dan selanjutnya dapat melakukan analisis jalus;

(b) Sebaliknya, jika harga GFI dan AGFI mendekati angka 0 , berarti model yang dikonstruksikan tidak sesuai dan selanjutnya lebih baik mengganti modelnya.

Berdasarkan hasil analisis data, diperoleh harga $\mathrm{GFI}=0,96$ dan $\mathrm{AGFI}=0,94$ yang berarti model yang telah dikonstruksikan secara teoritik dapat diterima secara empirik. Hal ini mengisyaratkan bahwa proses pengujian jalur dapat dilakukan.

Berikutnya adalah mencari harga koefisien jalur masing-masing struktur pasangan variabel. Hal ini mutlak dilakukan untuk menentukan besaran pengaruh variabel berdasarkan jalurnya. Berdasarkan hasil analisis data, harga koefisien jalur untuk masing-masing struktur dapat dilihat pada tabel berikut.

Tabel 3. Harga Koefisien Jalur Untuk Masing-Masing Struktur

\begin{tabular}{|c|c|c|c|c|c|}
\hline \multirow[t]{2}{*}{ Jalur } & \multirow{2}{*}{$\begin{array}{c}\text { Koefisien } \\
\text { Jalur }\end{array}$} & \multirow[t]{2}{*}{$\mathbf{t}_{\text {hitung }}$} & \multicolumn{2}{|c|}{$t_{\text {tabel }}$} & \multirow[t]{2}{*}{ Keterangan } \\
\hline & & & $\alpha=0,05$ & $\alpha=0,01$ & \\
\hline $\mathrm{p}_{41}$ & 0,41 & $3,76^{* *}$ & 1,96 & 2,56 & Sangat signifikan \\
\hline $\mathrm{p}_{42}$ & 0,24 & $2,14 * *$ & 1,96 & 2,56 & Sangat signifikan \\
\hline $\mathrm{p}_{43}$ & 0,37 & $3,11 * *$ & 1,96 & 2,56 & Sangat signifikan \\
\hline $\mathrm{p}_{32}$ & 0,41 & $3,78 * *$ & 1,96 & 2,56 & Sangat signifikan \\
\hline $\mathrm{p}_{32}$ & 0,45 & $4,01 * *$ & 1,96 & 2,56 & Sangat signifikan \\
\hline
\end{tabular}

$* *=$ Signifikan pada $\alpha=0,01$

\section{Pengujian Hipotesis}

Pengaruh Langsung Pengembangan Karir $\left(X_{1}\right)$ terhadap Profesionalitas $\left(X_{4}\right)$

Hipotesis yang diuji adalah:

$\mathrm{H}_{0}: \mathrm{p}_{41}=0$
$\mathrm{H}_{1}: \mathrm{p}_{41}>0$

Hasil analisis data menyimpulkan bahwa harga koefisien jalur $\left(\mathrm{p}_{41}\right)=0,411$ dengan harga $t_{\text {hitung }}=3,78$. Pada sisi lain, harga $t_{\text {tabel }} \boldsymbol{\alpha}$ (alpha $=0,01)=2,56$. Hal ini berarti bahwa $t_{\text {hitung }}=3,78>t_{\text {tabel }}=2,56$ yang berarti $H_{o}$ 
ditolak dan $\mathrm{H} 1$ diterima. Artinya, koefisien alu ini sangat signifikan. Dengan demikian, dapat disimpulkan bahwa pengembangan karir berpengaruh langsung positif terhadap profesionalitas. Artinya, perbaikan pengembangan karir akan meningkatkan profesionalitas.

Pengaruh Langsung Iklim Organisasi $\left(X_{2}\right)$ terhadap Profesionalitas $\left(\mathrm{X}_{4}\right)$

Hipotesis yang diuji adalah:

$\mathrm{H}_{0}: \mathrm{p}_{42 \leq} 0$

$\mathrm{H}_{1}: \mathrm{p}_{42}>0$

Hasil analisis data menyimpulkan bahwa harga koefisien jalur $\left(\mathrm{p}_{42}\right)=0,24$. Harga $t_{\text {hitung }}=2,14$. Angka ini lebih kecil jika dibandingkan dengan $\mathrm{t}_{\text {tabel }}$ untuk $(\boldsymbol{\alpha}=0,01)$ $=2,56$. Tetapi lebih besar untuk $(\boldsymbol{\alpha}=0,05)=$ 1,96. Fakta ini mengungkapkan bahwa $\mathrm{t}_{\text {hitung }}=2,14>\mathrm{t}_{\text {tabel }}=1.96$ yang berarti $\mathrm{H}_{0}$ ditolak dan $\mathrm{H}_{1}$ diterima. Artinya, koefisien jalur ini sangat signifikan. Temuan ini mengandung arti bahwa iklim organisasi $\left(\mathrm{X}_{2}\right)$ berpengaruh langsung positif terhadap profesionalitas $\left(\mathrm{X}_{4}\right)$.

Pengaruh Langsung Kepuasan Kerja $\left(X_{3}\right)$ terhadap Profesionalitas $\left(\mathrm{X}_{4}\right)$

Hipotesis yang diuji adalah:

$\mathrm{H}_{0}: \mathrm{p}_{43} \leq 0$

$\mathrm{H}_{1}: \mathrm{p}_{43}>0$

Hasil analisis data menyimpulkan bahwa harga koefisien jalur $\left(\mathrm{p}_{43}\right)=0,37$ dengan harga $t_{\text {hitung }}=3,11$. Pada sisi lain, harga $t_{\text {tabel }} \boldsymbol{\alpha}$ $($ alpha $=0,01)=2,56$. Fakta ini menegaskan bahwa $t_{\text {hitung }}=3,11>t_{\text {tabel }}=2,56$ yang berarti $\mathrm{H}_{0}$ ditolak dan $\mathrm{H}_{1}$ diterima. Artinya, koefisien jalur ini sangat signifikan. Temuan ini menegaskan bahwa kepuasan kerja $\left(\mathrm{X}_{3}\right)$ berpengaruh langsung positif terhadap profesionalitas $\left(\mathrm{X}_{4}\right)$.

Pengaruh Langsung Pengembangan Karir (X1) Terhadap Kepuasan Kerja (X3)

Hipotesis yang diuji adalah:

$\mathrm{H}_{0}: \mathrm{p}_{31} \leq 0$

$\mathrm{H}_{1}: \mathrm{p}_{31}>0$

Hasil analisis data menyimpulkan bahwa harga koefisien jalur $\left(\mathrm{p}_{31}\right)=0,45$. Pada sisi lain, diperoleh juga harga $t_{\text {hitung }}=4,01$. Sedangkan harga $\mathrm{t}_{\text {tabel }} \boldsymbol{\alpha}($ alpha $=0,01)=2,56$. Fakta ini menegaskan bahwa $\mathrm{t}_{\text {hitung }}=4,01>$ $\mathrm{t}_{\text {tabel }}=2,56$ yang berarti $\mathrm{H}_{0}$ ditolak dan $\mathrm{H} 1$ diterima. Artinya, koefisien jalur ini sangat signifikan. Temuan ini menyimpulkan bahwa pengembangan karir $\left(\mathrm{X}_{1}\right)$ berpengaruh langsung positif terhadap kepuasan kerja $\left(\mathrm{X}_{3}\right)$.

Pengaruh Langsung Iklim Organisasi $\left(\mathrm{X}_{2}\right)$ terhadap Kepuasan Kerja $\left(X_{3}\right)$

Hipotesis yang diuji adalah:

$\mathrm{H}_{0}: \mathrm{p}_{32} \leq 0$

$\mathrm{H}_{1}: \mathrm{p}_{32}>0$

Berdasarkan hasil perhitungan data, diperoleh informasi bahwa harga koefisien jalur $\left(p_{32}\right)=0,41$. Harga $t_{\text {hitung }}=4,76$. dan harga $t_{\text {tabel }} \boldsymbol{\alpha}($ alpha $=0,01)=2,56$. Fakta ini mengungkapkan bahwa $t_{\text {hitung }}=4,01>t_{\text {tabel }}=$ 2,56 yang berarti $\mathrm{H}_{0}$ ditolak dan $\mathrm{H} 1$ diterima. Artinya, koefisien jalur ini sangat signifikan. Temuan ini menyimpulkan bahwa iklim organisasi $\left(\mathrm{X}_{2}\right)$ berpengaruh langsung positif terhadap kepuasan kerja $\left(\mathrm{X}_{3}\right)$.

Temuan penelitian ini dapat dirangkum dalam Gambar sebagai berikut: 


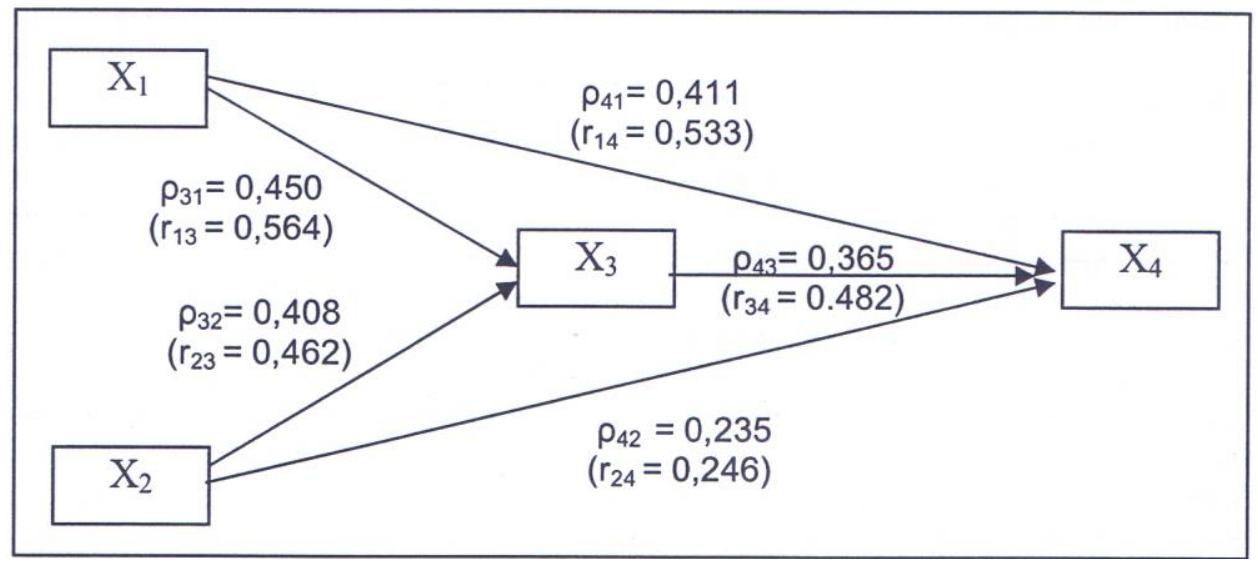

Gambar 2. Rangkuman Temuan Penelitian

\section{PENUTUP}

\section{Simpulan}

Berdasarkan hasil perhitungan statistik yang telah diuraikan pada bab sebelumnya, temuan penelitian ini dapat diuraikan sebagai berikut:

1. Terdapat pengaruh langsung positif pengembangan karier terhadap profesionalitas;

2. Terdapat pengaruh langsung positif iklim organisasi terhadap profesionalitas;

3. Terdapat pengaruh langsung positif kepuasan kerja terhadap profesionalitas;

\section{DAFTAR PUSTAKA}

Flippo, E. B. (2009). Manajemen Personalia, terjemahan Moh Masud. Jakarta: Erlangga

Koehn, D. (2000). Landasan Etika Profesi, terjemahan Agus M. Hidayat. Jakarta: Kainisius.

Luthans, F. (2008). Organizational Behavior. New York: McGraw-Hill, Inc.

Mullins, L. J. (2005). Management and Organisational Bahavior. New Jersey: Prentice Hall.
4. Terdapat pengaruh langsung positif pengembangan karier terhadap kepuasan kerja;

5. Terdapat pengaruh langsung positif iklim organisasi terhadap kepuasan kerja.

Berdasarkan temuan penelitian di atas, dapat disimpulkan bahwa pengembangan karier, iklim organisasi, dan kepuasan kerja berpengaruh terhadap profesionalitas, baik secara langsung maupun tidak langsung. Dengan kata lain, profesionalitas dapat ditingaktakn melalui pengembangan karier, iklim organisasi, dan kepuasan kerja.

Newstorm, J. W., dan Davis, K. (2002). Organizational Behavior: Human Behavior at Work. New Delhi: Tata McGraw-Hill Publishing Co.

Robbins, S. P. (2008). Organizational Behavior. New Jersey: Prentice Hall

Schermerhorn, J. R., Hunt, J. G., and Osborn, R. N. (2007). Managing Organizational Behavior. New York: John Wiley \& Sons. 
Sudjana. (2004). Metode Statistik. Bandung: Tarsito.

Sugiyono. (2008). Metod Penelitian Pendidikan. Bandung: Alfabeta.

Usman, M. U. (2001). Menjadi Guru Profesional. Bandung: Remaja Rosadakarya.

Wexley, K. N., and Yukl, G. A. (2005). Perilaku Organisasi dan Psikologi Manajemen, Terjemahan Muh. Shobaruddin. Jakarta: Rineka Cipta.

Wirawan. (2002). Profesi \& Standar Evaluasi. Jakarta: Yayasan Bangun Indonesia \& UHAMKA Press. 